\title{
Specific features of telomerase RNA from Hansenula polymorpha
}

\author{
ELENA M. SMEKALOVA, ${ }^{1,2,5}$ ALEXANDER N. MALYAVKO, ${ }^{1,2,5}$ MARIA I. ZVEREVA, ${ }^{1,2,6}$ ANDREY V. MARDANOV, ${ }^{3}$ \\ NIKOLAI V. RAVIN, ${ }^{3}$ KONSTANTIN G. SKRYABIN, ${ }^{3}$ ERIC WESTHOF, ${ }^{4}$ and OLGA A. DONTSOVA ${ }^{1,2}$ \\ ${ }^{1}$ Faculty of Chemistry, Lomonosov Moscow State University, 119999 Moscow, Russia \\ ${ }^{2}$ Belozersky Institute, Moscow State University, 119991 Moscow, Russia \\ ${ }^{3}$ Centre Bioengineering of RAS, Moscow 117312, Russia \\ ${ }^{4}$ Architecture et Réactivité de I'ARN, Université de Strasbourg, Institut de Biologie Moléculaire et Cellulaire du CNRS, F-67084 Strasbourg, France
}

\begin{abstract}
Telomerase, a ribonucleoprotein, is responsible for the maintenance of eukaryotic genome integrity by replicating the ends of chromosomes. The core enzyme comprises the conserved protein TERT and an RNA subunit (TER) that, in contrast, displays large variations in size and structure. Here, we report the identification of the telomerase RNA from thermotolerant yeast Hansenula polymorpha (HPTER) and describe its structural features. We show further that the H. polymorpha telomerase reverse transcribes the template beyond the predicted boundary and adds a nontelomeric dT in vitro. Sequencing of the chromosomal ends revealed that this nucleotide is specifically present as a terminal nucleotide at the $3^{\prime}$ end of telomeres. Mutational analysis of HPTER confirmed that the incorporation of dT functions to limit telomere length in this species.
\end{abstract}

Keywords: telomerase RNA; telomere biogenesis

\section{INTRODUCTION}

Telomerase is a unique enzyme, which is capable of synthesizing telomeric DNA, templated by its own RNA subunit; the main function of this complex is to maintain telomere length (Blackburn 2000). The core components-telomerase reverse transcriptase (TERT) and telomerase RNA (TER)—are sufficient to maintain in vitro telomerase activity, although in vivo additional cellular factors are required for proper function of the enzyme (Collins 2006). TERT is known to be an evolutionary conserved reverse transcriptase (Lingner et al. 1997). TER varies greatly among species and its size ranges from $150 \mathrm{nt}$ in ciliates to $450 \mathrm{nt}$ in vertebrates and reaches $2000 \mathrm{nt}$ in yeast (Theimer and Feigon 2006; Kachouri-Lafond et al. 2009). Mutational, structural, and phylogenetic studies revealed the presence of a few elements of higher order structure, which are required for enzymatic functions among all species and are similar among related organisms (Theimer and Feigon 2006). However, TER primary sequence is difficult to align even between closely related species.

The short length of the template is compensated by the ability of the enzyme to translocate newly synthesized DNA repeatedly to the beginning of the template, a process termed

${ }^{5}$ These authors contributed equally to this work.

${ }^{6}$ Corresponding author

E-mail zvereva@genebee.msu.ru

Article published online ahead of print. Article and publication date are at http://www.rnajournal.org/cgi/doi/10.1261/rna.038612.113. repeat addition processivity (Lue 2004). This feature varies between telomerases from different species, especially for enzymes studied in vitro. For example, ciliate or human telomerase can add hundreds of telomeric repeats to the substrate; Tetrahymena thermophila enzyme is processive, but starting from the second repeat, the efficiency of synthesis is largely reduced; yeast telomerases are usually nonprocessive, with rare exceptions such as the Saccharomyces castellii telomerase complex (Greider 1991; Cohn and Blackburn 1995; Lue 2004).

We focused our research on a telomerase from the thermotolerant yeast, Hansenula polymorpha, also known as Pichia angusta, which is able to grow under temperatures $>50^{\circ} \mathrm{C}$ (Levine and Cooney 1973); thus, one can expect that its components-both proteins and nucleic acids-will be more stable. $H$. polymorpha belongs to a limited number of methylotrophic yeast and taxonomically is a member of the Saccharomycetaceae family. A recently published analysis of the mitochondrial genome of $H$. polymorpha (strain DL-1), its content, and gene order revealed a close phylogenetic relationship between $H$. polymorpha and Brettanomyces custersianus and suggested that these species should be assigned to a separate genus rather than included in the polyphyletic genus

(C) 2013 Smekalova et al. This article is distributed exclusively by the RNA Society for the first 12 months after the full-issue publication date (see http:// rnajournal.cshlp.org/site/misc/terms.xhtml). After 12 months, it is available under a Creative Commons License (Attribution-NonCommercial 3.0 Unported), as described at http://creativecommons.org/licenses/by-nc/3.0/. 
of Pichia (Eldarov et al. 2011). Telomeres of H. polymorpha were reported to consist of the highly regular pattern $5^{\prime}$ GGGTGGCG-3' repeated 18-23 times (Sohn et al. 1999), which is shorter than the telomeres in other known species. The fact that $H$. polymorpha stands at the crossroads between different yeast species makes it particularly interesting to identify its telomerase RNA and investigate telomerase properties.

In this study, we report the identification of the telomerase RNA subunit HpTER. We present the secondary structure model of HpTER and compare its functional elements with other known telomerase RNAs. Characterization of telomerase activity in $H$. polymorpha revealed that after generating a telomeric repeat in vitro the enzyme efficiently synthesized a dT nucleotide, which was not present in telomeres at this position. Direct sequencing of telomeric ends showed that in vivo $\mathrm{dT}$ is incorporated only at the very end of telomeres. We confirmed the importance of this event in vivo by mutating telomerase RNA and analysis of telomere length in mutant strains. Mutants, which did not provide a basis for the synthesis of terminal mismatching sequence, possessed extended and heterogeneous telomeres. These results imply that $H$. polymorpha telomerase utilizes reverse transcription of nontelomeric nucleotide to control telomere elongation.

\section{RESULTS}

\section{Identification of the candidate for $\boldsymbol{H}$. polymorpha telomerase RNA}

Genome sequence data from $H$. polymorpha strain DL-1 were obtained [the complete DNA sequence of $H$. polymorpha DL-1 is available from Genbank (AEOI01000001.1AEOI01000013.1)]. A search for a putative ortholog of known yeast telomerase RNAs in the $H$. polymorpha genome did not yield any candidate, which is consistent with the fact that the RNA subunit is evolutionarily variable. We therefore used a biochemical approach to identify the gene of interest. The experiment was based on the strategy described previously for the identification of $S$. pombe telomerase RNA (Leonardi et al. 2008; Webb and Zakian 2008). We used recombinant $H$. polymorpha TERT (Smekalova et al. 2012) to obtain antibodies for the immunoprecipitation of the telomerase complex. The $H$. polymorpha telomerase was isolated by partial purification of S100 extract derived from wild-type $H$. polymorpha cells on a DEAE sepharose column as described previously (Cohn and Blackburn 1995). For the visualization of telomerase activity in DEAE fractions, a classical direct assay was performed with the use of the $13 \mathrm{nt}$ telomere-like primer HD1 (5'-GGGTGGCGGGGTG-3') constructed using the sequence data for the $H$. polymorpha chromosomal ends (Sohn et al. 1999). We detected RNA-dependent DNA polymerization products straight above the radio-end-labeled primer from DEAE fractions 8-10 containing 400-500 mM NaOAc (Supplemental Fig. S1A). Telomerase isolated by DEAE fractionation of the S100 extract was then further puri- fied by immunoprecipitation with HpTERT antibody. Partial retention of the telomerase activity on the beads proved the robustness of the approach (Supplemental Fig. S1B). Total RNA was recovered from the fractions enriched in telomerase activity and subjected to reverse transcription from terSearch primer (5'-GGGTGGCGG-3') generated with the known telomeric sequences and telomerase direct assays described above. The DNA product obtained in the first step was treated with terminal transferase to produce a G-tail on the $3^{\prime}$ end of the newly synthesized cDNA. PCR was performed from polyC and terSearch primer, followed by cloning and sequence analysis. This strategy revealed a candidate sequence matching the HPODL_contig07 of the Pichia angusta DL-1 position 711047-771215. Analysis of the locus showed that this region did not overlap with conserved ORFs. The PDD4 gene, functionally related to the Vps (Vacuolar protein sorting) family in S. cerevisiae, is located upstream of the candidate locus. Notably, a Vps homolog is also present at the $5^{\prime}$ region of the S. pombe telomerase RNA (Leonardi et al. 2008). Downstream from the putative HPTER gene (Hansenula polymorpha telomerase RNA), there is a conserved ORF showing high homology with Pichia pastoris aromatic amino acid aminotransferase 1 .

\section{Knockout of the HpTER gene leads to telomere shortening}

To determine whether disruption of the HPTER gene caused the predicted ever shorter telomere (EST) phenotype, we made a knockout of the HPTER gene. H. polymorpha TERT knockout was used as a control. The DL1-1 strain used in this study is haploid under normal conditions and is a leucine auxotroph. A large part of the HPTER gene, including the putative template region, was replaced with an HpLEU2 marker (Agaphonov et al. 1994). In the case of HPTERT, a selective marker was introduced in the middle of the coding region, disrupting the protein synthesis. After isolation of the deficient strains, the DNA products of the predicted length were detected by PCR analysis, which confirmed the robustness of the integration (Supplemental Fig. S2). The phenotype of two independent $\triangle$ HpTER transformants, the wild-type and the HPTERT deficient strain, was observed over time. Loss of cell viability could be detected from the first streak on the plate, which represented around 20 generations after the depletion of the gene (Fig. 1A). H. polymorpha chromosomes initially possess short telomeres (140-190 nt) (Sohn et al. 1999). Starting from the second restreak, null cells from liquid culture were unable to give rise to new colonies on the plate (Fig. 1A). Post senescent survivors appearing for both types of mutant cells from liquid culture after several restreaks (Fig. 1A) are most likely to be a result of homologous recombination (IJpma and Greider 2003; Kachouri-Lafond et al. 2009).

The telomere length in these strains was analyzed by Southern blot of terminal restriction fragments with a 


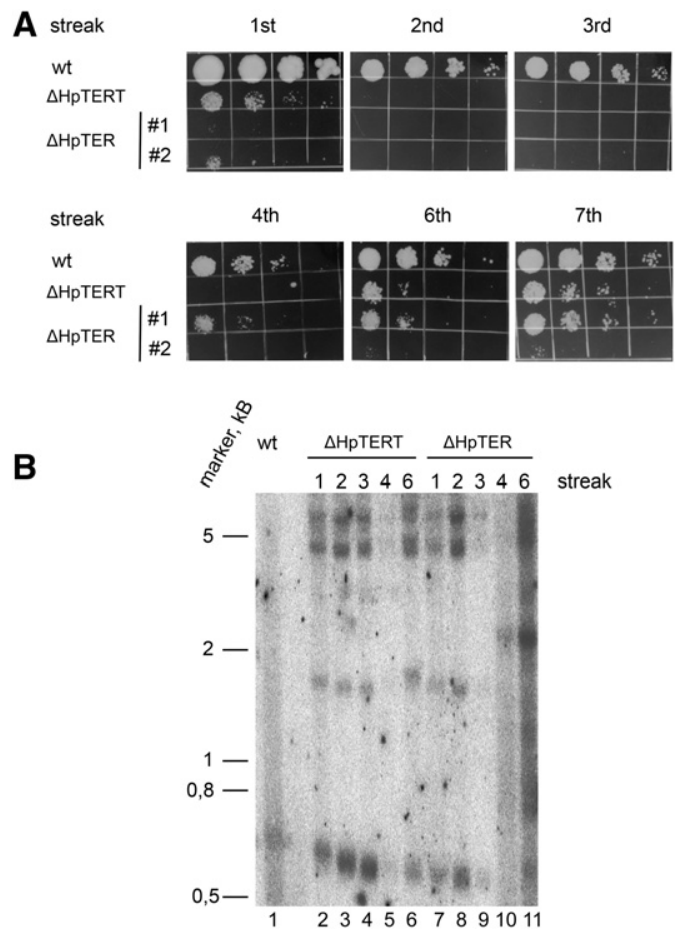

FIGURE 1. Analysis of the $H p T E R$ gene that encodes telomerase RNA in H. polymorpha. (A) Deletion of either HpTERT or HpTER gene led to loss of cell viability, followed by senescence and appearance of survivors (see Materials and Methods for the detailed description). (B) Southern blot analysis of terminal restriction fragments for DNA from wild-type (wt) strain (lane 1), $\triangle$ HpTERT strain (lanes 2-6: streaks 1,2,3,4,6, respectively), and $\triangle$ HpTER strain (lanes 7-11: streaks 1,2,3,4,6, respectively). $\triangle$ HpTER\#1 transformant was used in this experiment.

telomeric probe. The Southern blot showed that the telomere fragments underwent shortening immediately from the first restreak for the knockout strains (Fig. 1B). Together with the cell viability data, these results confirm the EST phenotype for strains deficient in HPTERT and HPTER.

To confirm that this phenotype was the result of HPTER deletion itself, we cloned the HPTER gene, including $150 \mathrm{nt}$ upstream as the native promoter into the shuttle vector. We inserted this construct into the $\Delta$ HpTER knockout strain. Cell viability as well as telomerase activity was restored in this strain (Supplemental Fig. S3).

After the introduction of a plasmid, colonies on the plate were present only in the case of functional telomerase RNA on the plasmid; an empty vector without $H p T E R$ gene or with a nonfunctional mutant $H P T E R$ gene did not yield any colonies on the plate under transformation conditions (Supplemental Fig. S3A).

\section{HPTER transcript is present in several forms in vivo}

The $5^{\prime}$ end of HpTER was defined from the strategy applied before for the identification of the telomerase RNA candidate. The $5^{\prime}$ end, in three of six sequences, began at the same position $168 \mathrm{nt}$ upstream of the putative template region; one clone started $170 \mathrm{nt}$ upstream and two others began 119 and $120 \mathrm{nt}$ upstream of the putative template region (Supplemental Fig. S4). In order to map the $5^{\prime}$ end more precisely, $5^{\prime}$ RACE was performed on total RNA. This resulted in eight clones, seven of which placed the $5^{\prime}$ end at $168 \mathrm{nt}$ and one at $169 \mathrm{nt}$ upstream of the putative template region.

To define the $3^{\prime}$ end position of HpTER, RACE strategy was applied. The total RNA was isolated from the cells under mild conditions, and half the RNA was treated with polyA polymerase to add a polyA tail to the RNA $3^{\prime}$ end. cDNAs were obtained from both samples with a primer that consisted of oligo-dT and an adaptor. The cDNA was then subjected to PCR with the adaptor primer and the second primer specific to telomerase RNA. PCR fragments were subcloned and sequenced (Supplemental Fig. S4). The majority of naturally polyadenylated products had a $3^{\prime}$ end at position 792 (10 of 18); the longest product corresponded to $816 \mathrm{nt}$. One of the sequences lacked a possible intron (highlighted in Fig. 2). Six of the 25 sequences with naturally nonpolyadenylated RNA had a $3^{\prime}$ end at position 689 . The most abundant product (10 of 25 ) had the $3^{\prime}$ end located at position 680 (Fig. 2).

A similar approach was applied to identify a $3^{\prime}$ end of HpTER in DEAE-isolated telomerase fraction. Naturally, polyA-containing products belonged to the same RNA region, the longest form was $824 \mathrm{nt}$ in length (Supplemental Fig. S4). The nonpolyadenylated forms were the same or shorter than in the previous case (672-680 and 584-590).

\section{HPTER secondary structure model}

We predicted an HpTER secondary structure by combining several approaches. The Mfold web server (Zuker 2003) was used to determine overall HpTER architecture. The output was then adjusted according to existing data on particular functional elements of yeast telomerase RNAs with the help of the S2S program (Jossinet and Westhof 2005). The results are shown in Figure 2.

Mfold prediction yielded two alternative structures for the putative template boundary element (TBE) (Supplemental Fig. S5A,B). To distinguish between them, we performed mutagenesis that confirmed TBE structure "A." Two distinct mutations, ${ }^{163} \mathrm{GCG} / \mathrm{CGC}^{161}$ and ${ }^{128} \mathrm{CGC} / \mathrm{GCG}^{130}$, were made to destroy stem element, whereas the combination of mutations restored the helix (Supplemental Fig. S5A). In accordance with the model, cells transformed with mutant ${ }^{128} \mathrm{CGC} /$ GCG $^{130}$, displayed an Est phenotype, whereas the combination of those mutations restored cell viability (Supplemental Fig. S5C). In Figure 2, the putative stem structure confirmed by this analysis is displayed.

Putative splicing is shown in the TER model. To prove that predicted splicing determinants are functional, we mutated 5'-ss (G690A_TGAGT) and branch point site (TACTA_ A725C_C) in the HpTER gene. Corresponding shuttle vectors were then transferred into a strain deficient in $H p T E R$. In case 


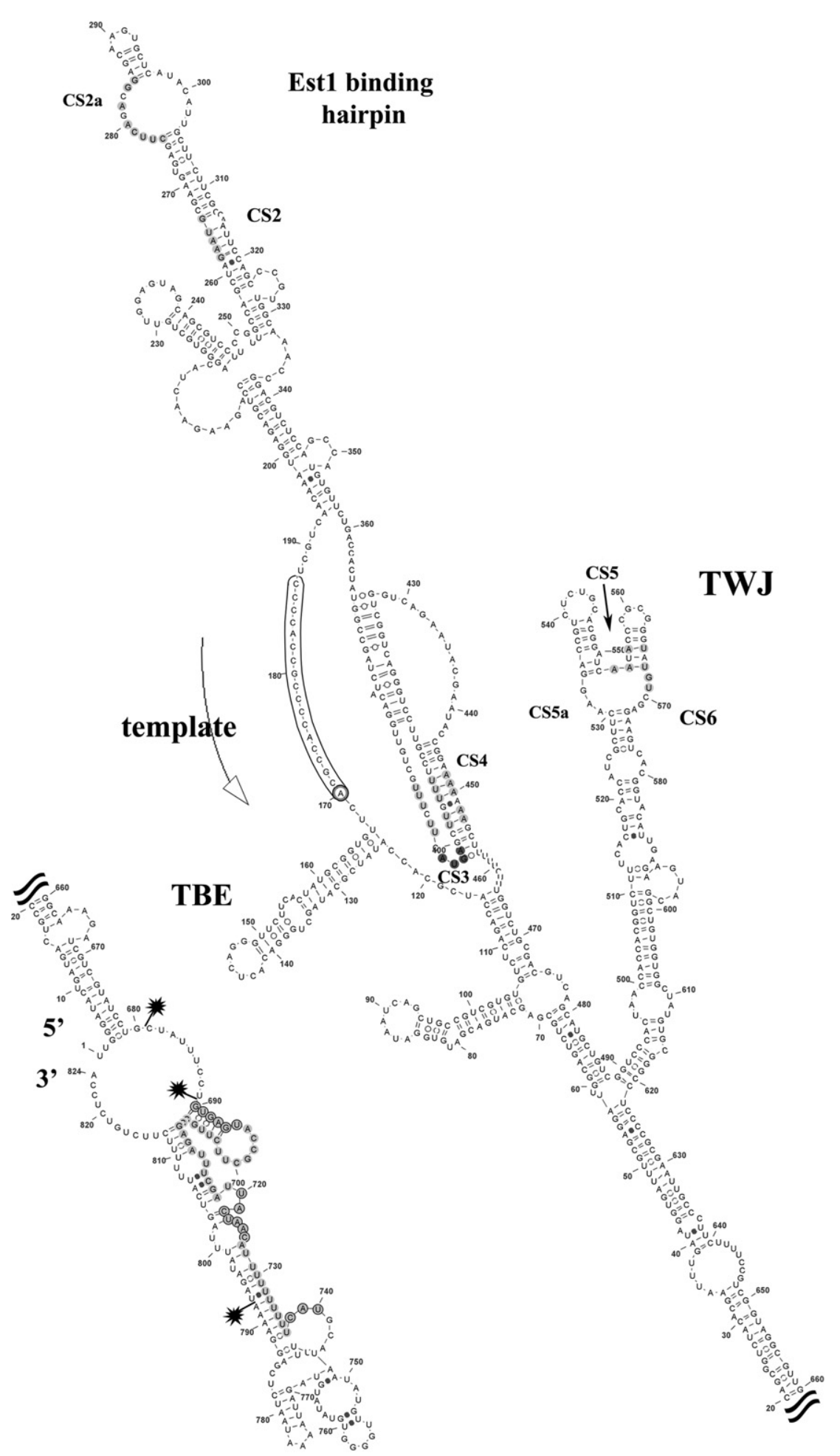

FIGURE 2. HpTER secondary structure model. The complete HpTER architecture is represented with functional elements marked. The template region is outlined with A170 nucleotide additionally marked with a gray circle. The pseudoknot forming nucleotides (those participating in the formation of triple helix), the nucleotides in Est1 binding hairpin (conserved for Candida species), and the nucleotides within the three-way junction (TWJ) element (conserved among all studied telomerase RNA) are marked in light gray. Nucleotides in the CS3 element, conserved for budding yeast, are highlighted in dark gray. Intronic sequence is also highlighted in light gray, with the $5^{\prime}$ splice site, branch point, and presumable $3^{\prime}$ splice site outlined. The drawing was obtained using the VARNA web server (Darty et al. 2009). of the branch point mutant, we could not obtain any transformant (Supplemental Fig. S6A). The 5'ss mutant was viable; however, the amount of HpTER transcript measured by real-time RT-PCR in the strain was ten times lower compared to the wild type (Supplemental Fig. S6B).

\section{Characterization of the telomerase activity from $H$. polymorpha}

To identify the DNA sequence synthesized by the $H$. polymorpha telomerase, we performed a reaction in which one of the three nucleotides $(\mathrm{dA}, \mathrm{dT}$, and dC) was substituted by its dideoxy analog (Fig. 3A). For this experiment, the G4 primer $\left[5^{\prime}-(\text { GGGTGGCG })_{4}-3^{\prime}\right]$ was used. Extension of G4 primer in the presence of ddT or ddC in the reaction resulted in a premature stop at the position expected from the template sequence (Fig. 3A, lanes 4,5). Accordingly, the addition of $\mathrm{ddA}$ in the reaction mixture did not change the primer elongation pattern (Fig. 3A, lane 3). The H. polymorpha telomerase acted in a nonprocessive manner in vitro and did not produce more than one repeat.

Since $H$. polymorpha is a thermotolerant organism, we addressed the question whether its telomerase in vitro is active at higher temperatures. Optimum growth conditions for these species are known to be $37^{\circ} \mathrm{C}$. Reactions were performed with the $\mathrm{G} 4$ primer from $4^{\circ} \mathrm{C}$ to $70^{\circ} \mathrm{C}$. The fractions containing telomerase and reaction mixtures were preheated for $2 \mathrm{~min}$ at the desired temperature. In spite of the fact that $H$. polymorpha strains are able to survive at $50^{\circ} \mathrm{C}$, telomerase activity in vitro could be detected only up to temperatures of $35^{\circ} \mathrm{C}$ (Fig. 3B). In contrast, lower temperatures do not seem to affect enzymatic activity much, and even at $4^{\circ} \mathrm{C}$, the telomerase produced elongation of the primer up to four nucleotides.

\section{H. polymorpha telomerase reverse transcribes beyond the predicted template boundary in vitro}

Comparison of the HpTER to the telomeric sequence revealed a region between 171 and $187 \mathrm{nt}$ (more than two repeats), 


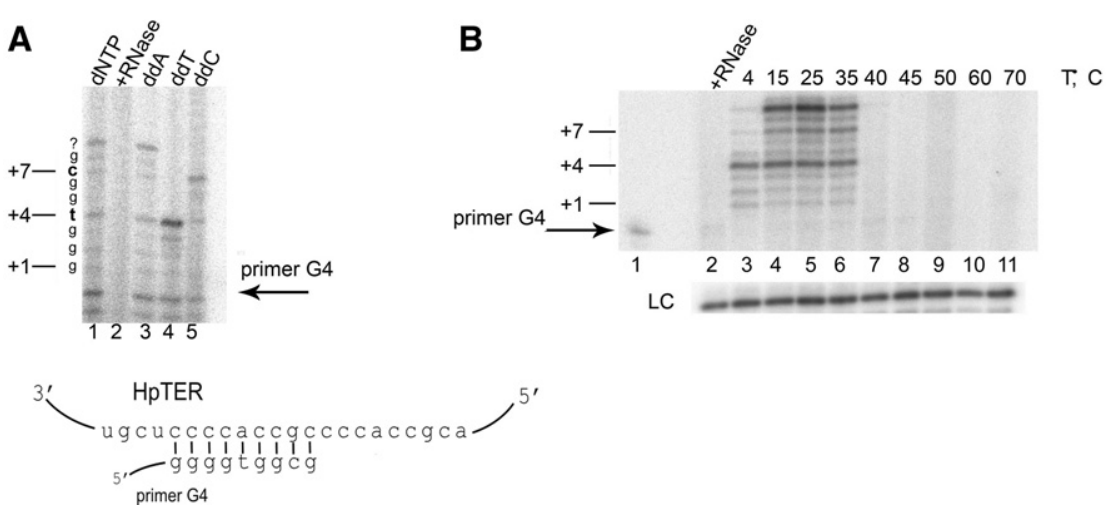

FIGURE 3. Characterization of the telomerase activity from $H$. polymorpha. (A) Analysis of the sequence of the product added by telomerase to G4 primer. Lane 1: telomerase assay in presence of dNTP mixture. Lane 2: The sample first treated by RNase A was then used for telomerase assay. Lanes 3-5: ddATP, ddTTP, ddCTP were added to the reaction mixture as indicated. The sequence added to the G4 primer is shown at the left side of the gel. The position of 5'-phosphorylated G4 primer is marked by an arrow. The scheme of primer alignment along HpTER template is shown below the gel. The resulting pattern was consistent with telomeric sequence. (B) Analysis of telomerase activity at different temperatures. Lane 1: position of the $5^{\prime}$-phosphorylated G4 primer (marked by an arrow). Lane 2: telomerase reaction after RNase treatment. Lanes 3-11: telomerase activity under corresponding temperature. A 5'-labeled 20-mer oligonucleotide was used as a loading control (LC).

which could serve as a template for telomere synthesis (Fig. 2). To determine the exact region used as template, we mutated C176 to adenosine in the HPTER gene. The mutated gene was introduced into the shuttle vector, transferred into a yeast cell, and purified telomerase from the strain was obtained. When ddT was present in the telomerase assay, the preliminary stop could be clearly seen at the position corresponding to the C176A mutation (Fig. 4A, lane 6). This result confirmed that nucleotides 178-171 of HpTER are reverse transcribed. Analysis of the nucleotide pattern added by the enzyme showed that the telomerase added nine nucleotides to the G4 oligonucleotide, although the template provided only eight nucleotides complementary to the annotated telomeric sequence in $H$. polymorpha. According to the telomeric sequence, the primer G4 [5'-(GGGTGGCG) ${ }_{4}-3^{\prime}$ ] should have been followed by the eight nucleotides 5'-GGGTGGCG-3'. That was partially verified in the previous experiment (Fig. $3 \mathrm{~A}$ ), which showed that the fourth and seventh nucleotides added were thymidine and cytidine, respectively.

To identify the additional nucleotide, we performed a reaction with the primer HD1 (5'-GGGTGGCGGGGTG-3'), which should align to the middle of the template region (Fig. 4B), and different sets of nucleotides were used to reveal the sequence added by the telomerase. In the presence of only radiolabeled dGTP*, one nucleotide was incorporated into the DNA (Fig. 4B, lane 1); dGTP* plus dCTP gave a pattern of three nucleotides; the incorporation of the fourth nucleotide took place only if dTTP was present in the reaction mixture (Fig. 4B, lane 3). From this experiment, we concluded that the added sequence was $5^{\prime}$-GCGT- $3^{\prime}$ and that the last incorporated nucleotide was reverse transcribed from adenine 170 , which was positioned beyond the predicted boundary.

\section{Telomerase cannot use the sequence produced in vitro}

Since the $H$. polymorpha telomerase DNA elongation product synthesized in vitro cannot align perfectly to the beginning of the template region, we wanted to test whether $H$. polymorpha telomerase can elongate the oligonucleotide corresponding to the sequence produced in vitro. We used a G4t oligonucleotide [5'-(GGGTGGCG) ${ }_{3}$ GGGTGGCGT-3'] that contains the nontelomeric thymidine at the end of the sequence. We observed a lack of signal in lane 1 (G4t substrate) compared to lane 2 (telomeric G4 substrate) (Fig. 4C), indicating the inability of the telomerase to use the DNA produced by in vitro reverse transcription.

\section{Occurrence of the nontelomeric nucleotide at telomeres in vivo}

To elucidate whether the sequence $5^{\prime}$ GGGTGGCGT- $3^{\prime}$ was present in internal telomere regions, we analyzed 87 reads from $H$. polymorpha whole genome shotgun sequences that displayed from 13 to 20 telomeric repeats (Supplemental File S1). Among the approximately 1400 analyzed repeats there was not a single case of thymidine positioned after $5^{\prime}$-GCG- $3^{\prime}$. After the sequence $5^{\prime}$-TGGC-3', we detected some heterogeneity involving different numbers of Gs $(6.7 \%$ and $4.5 \%$ of the telomeric repeats contained five and three Gs at this position instead of the four encoded by the telomerase RNA template).

Since the additional nucleotide was not found in the analysis of contigs obtained from genome sequencing, the special procedure for determining the terminal sequence of the ends of the chromosomes described previously (Leonardi et al. 2008) was applied. The direct pyrosequencing of chromosomal ends amplification products showed the presence of nontelomeric dT at the very end of telomeres (Supplemental Fig. S7). The analysis of the data according to the procedure described previously (Sfeir et al. 2005) is presented in Figure $4 \mathrm{D}$. Ninety percent of reads had extra nontelomeric $\mathrm{dT}$ as the last nucleotide of telomere sequences. Taken together, these data show that in vivo the extra nontelomeric dT residue is present only at the telomeric $3^{\prime}$ end.

\section{Reverse transcription of the A170 nucleotide is significant for telomere biogenesis in vivo}

To investigate the functional importance of the incorporation of the nontelomeric nucleotide at the very end of telomere, a number of mutations were introduced in the HpTER template region. First, we mutated A170 of the HpTER into two other nucleotides. Mutation A170C in the HPTER gene 

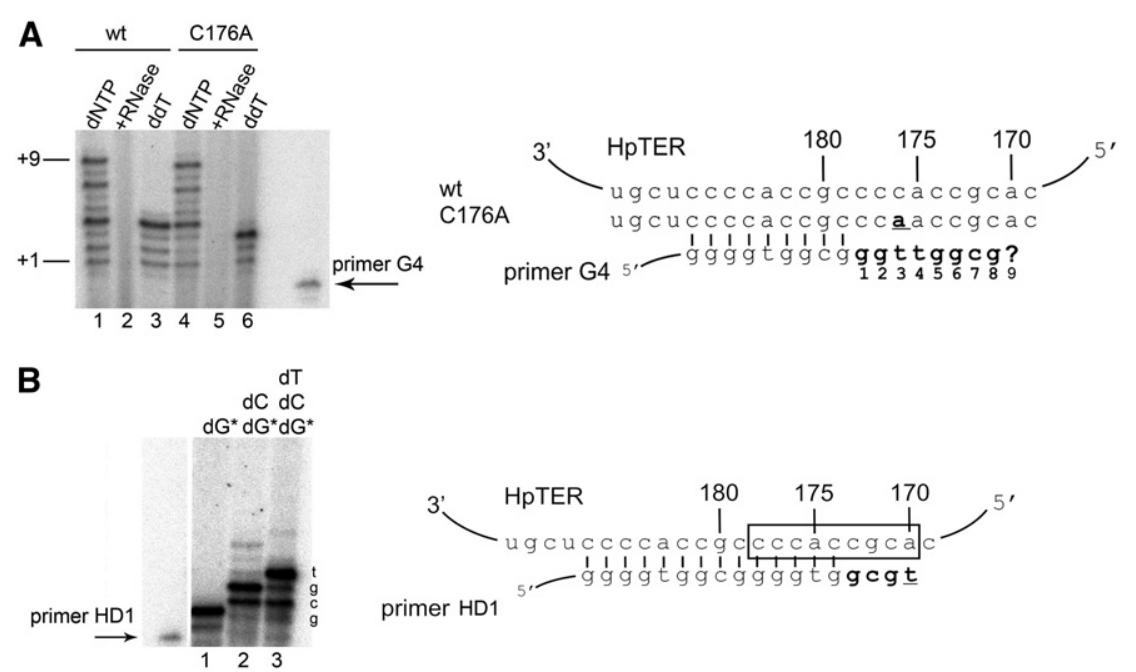

C

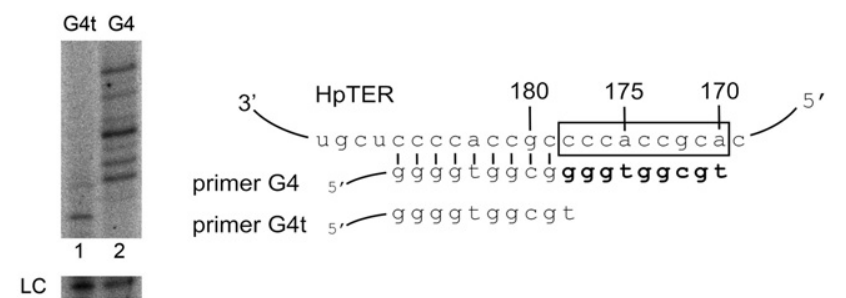

D

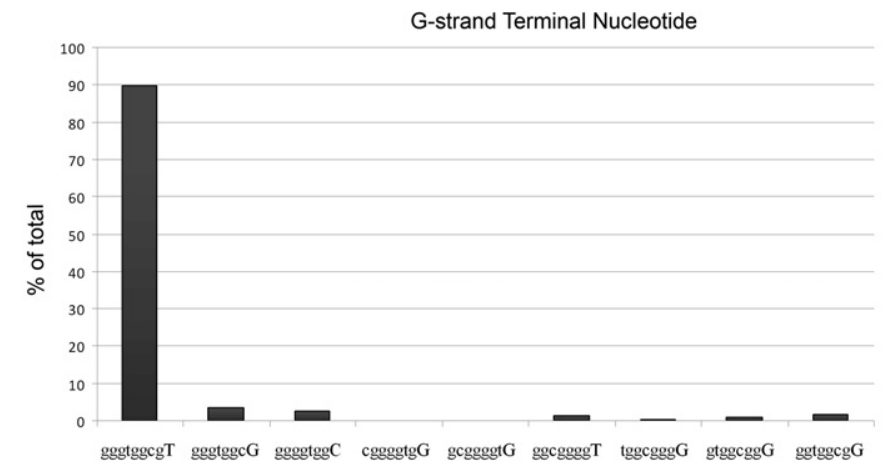

FIGURE 4. Reverse transcription of the nontelomeric nucleotide beyond the predicted template. (A) Telomerase activity assay for wt (lanes 1-3) and C176A mutant strains (lanes 4-6). Lanes 1,4: telomerase assay in presence of dNTP mixture. Lanes 2,5: after RNase treatment. Lanes 3,6: with ddTTP added to the reaction mixture. The position of incorporated nucleotide is indicated at the left side of the gel. Position of 5'-phosphorylated primer is shown at the right side of the gel. The scheme of the HpTER template region, sequence of the HpTER mutated in C176A position and G4 oligonucleotide aligned to the beginning of the template are represented alongside. Preliminary stop for C176A in case of ddT usage indicated that the HPTER gene served as telomerase RNA in $H$. polymorpha. Note that the primer was extended by $9 \mathrm{nt}$, whereas only $8 \mathrm{nt}$ could be added according to the template sequence encoding the telomeric pattern, the extra nucleotide is marked as "?" in the scheme. $(B)$ Analysis of the nature of the extra nucleotide reverse transcribed by $H$. polymorpha telomerase beyond the template. Telomerase activity assayed for wt enzyme: Lane 1: with HD1 oligonucleotide in presence of dGTP only; lane 2: with a mixture of dGTP and dCTP; lane 3: with a mixture of dGTP, dCTP, and dTTP. The position of the $5^{\prime}$-phosphorylated primer is shown at the left side of the gel. The scheme shows the alignment of HD1 primer along the HpTER template and telomerase elongation product (in bold letters). Addition of dT corresponding to the reverse transcription of A170 nucleotide in the telomerase RNA template region was revealed in lane 3. (C) Telomerase activity assay for wt telomerase with G4 primer (lane 1) and G4t primer (lane 2). (LC) loading control. The position of the primer alignment along HpTER template as well as the elongation product (in bold) is shown in the scheme. $(D)$ Analysis of the sequences of terminal telomeric PCR products. In total, 1248 terminal telomere repeats were analyzed. The percentage for each terminal nucleotide is shown on the diagram. should result in synthesis of a sequence corresponding fully to the telomeric one (Fig. 5A). A170G should produce the incorporation of a nontelomeric deoxycytidine in analogy to what is observed in the wild-type situation. An $H$. polymorpha strain lacking the endogenous $H p T E R$ gene was transformed with the vector containing the mutated HPTER. In the case of $\mathrm{A} 170 \mathrm{C}$, we detected a decrease in the efficiency of reverse transcription of C170 in comparison with A170 in a wild-type telomerase (Fig. 5B,C). Nevertheless, this strain could be used as a system to trace the fate of telomeres when the only sequence provided by telomerase is the telomeric one.

We analyzed telomere length by Southern blot in strains with mutated telomerase RNA (A170C, A170G), a wildtype strain and also a strain in which the HPTER knockout was compensated by the introduction of a plasmid containing wild-type telomerase RNA $\left(\triangle \mathrm{HpTER}^{+}\right)$. The shift of the radioactive signal to higher molecular weight indicated an elongation of telomeres in cells with the A170C mutation in HpTER compared to control strains. Further, the widening of the signal shows that telomeres became more heterogeneous (Fig. 5D, lanes 5,6, cf. to lanes 1-4). The A170G mutation, which produced nontelomeric $\mathrm{dC}$ incorporation, did not influence significantly telomere length and homogeneity (Fig. 5D, lanes $7,8$, cf. to lanes $1-4)$. We then made a double mutant in which the initial A170C mutation was preserved but with nucleotide C171 mutated to $\mathrm{A}$. In the double mutant A170C/C171A (noted AC170CA), telomeres became homogeneous and their lengths were similar to wt telomeres (Fig. 5E, lanes 3,4, cf. to lanes 1,2$)$. In the C178A mutant the end of the copied sequence of the telomerase RNA remains unchanged, but this mutation allows for the efficient rebinding of the $5^{\prime}$-GCGT- $3^{\prime}$ telomeric end (Fig. 5G). Indeed, Southern blot analysis of telomere length in the C178A mutant showed that telomeres became elongated and heterogeneous in the corresponding strain (Fig. 5E, lanes 7,8, cf. to lanes 5,6 for wt). Since high heterogeneity of bands in the Southern blots made it difficult to 
A

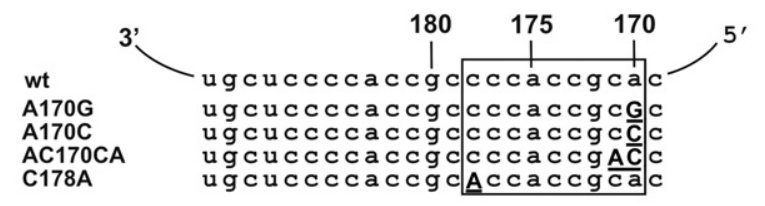

D
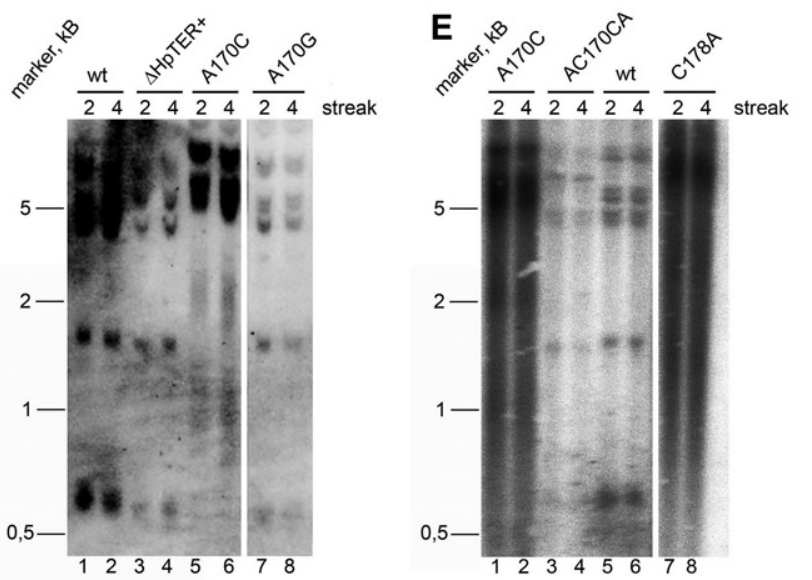

B

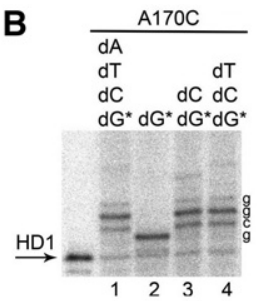

C

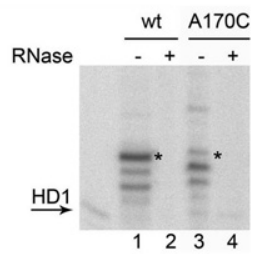

$\mathbf{F}$

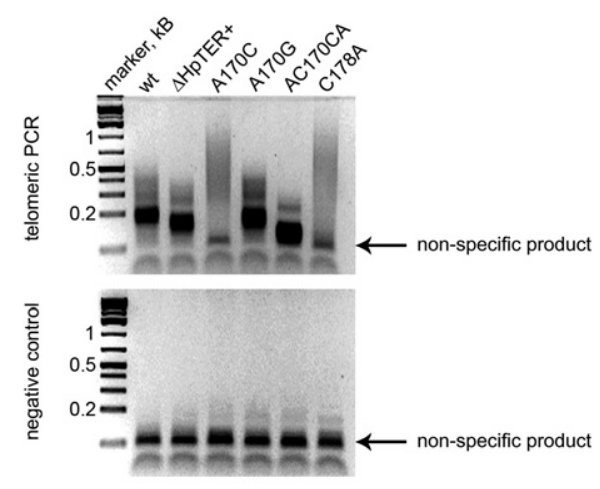

C178A

G $\quad$ A170C

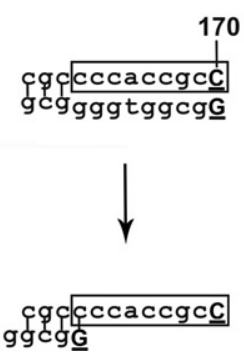

WT

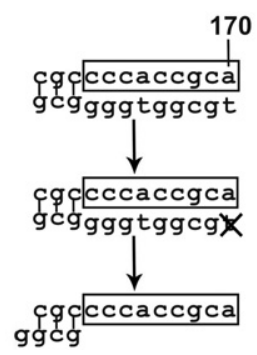

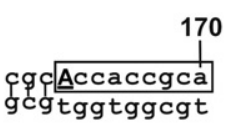

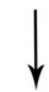

cgchaccaca

FIGURE 5. Mutational analysis of the telomerase RNA template region. (A) The list of the studied HpTER mutants. (B) Telomerase activity assay for the A170C mutant telomerase in presence of HD1 primer. Lane 1: in presence of dNTP; lane 2: dGTP; lane 3: dGTP and dCTP; lane 4: dGTP, dCTP and dTTP. The position of the $5^{\prime}$-phosphorylated HD1 primer is shown at the left side of the gel and marked by an arrow. The sequence added to the primer is indicated at the right side of the gel. (C) The telomerase activity of wt telomerase (lane 1) and in the A170C mutant (lane 3). Lanes 2-4: telomerase activity after RNase treatment of wt and mutant telomerase, respectively. The position of the 5'-phosphorylated HD1primer is marked by an arrow. Mutant telomerase reverse transcribes the nucleotide at position 170 less efficiently compared to wt enzyme. $(D)$ Southern blot analysis of telomeres in the strains carrying telomerase RNA, which was mutated at position 170. Lanes 1,2: for wt strain after second and fourth streak; lanes 3,4: for the strain expressing wt telomerase from the plasmid ( $\triangle \mathrm{HpTER}+)$; lanes 5,6: for A170C mutant; lanes 7,8: for A170G mutant. Mutation A170C in the telomerase RNA gene leads to elongation of telomeres and heterogeneity in their length. A different mutation A170G at the same position does not provide telomere lengthening. (E) Southern blot analysis of telomeres in strains after the second and fourth streak with mutations A170C (lanes 1,2), AC170CA (lanes 3,4), and C178A (lanes 5,6). The telomere elongation for A170C mutant is attenuated by the mutation of the following nucleotide 171. The effect of telomere elongation is reproduced in another mutant C178A. (F) The products of PCR of telomeres (separated in $2 \%$ agarose gel) from wild-type cells (wt and $\triangle \mathrm{HpTER}^{+}$) and mutants A170C, A170G, AC170CA, and C178A (upper). As a negative control, gDNA without duplex ligation was used (lower). Short nonspecific product appeared under PCR conditions without ligated primer is marked by an arrow. ( $G$ ) The scheme of the telomerase action for wt, A170C, and C178A mutant enzyme. Mutated nucleotides in HpTER template are in capital letters and underlined. After the synthesis of the telomeric repeat wt telomerase adds nontelomeric nucleotide $\mathrm{dT}$, which should be removed for the efficient realignment of the newly synthesized sequence. In case of both mutants, the last synthesized nucleotide matches always perfectly to the beginning of the template. As a result, telomeres become extended and heterogeneous in A170C and C178A mutants.

estimate the actual length of telomeres in the C178A mutant, an alternative approach for telomere length analysis was applied. We measured the telomere length by PCR amplification of particular telomere as it was done for terminal telomere sequencing. Telomere amplification products were then sepa- rated in the agarose gel (Fig. 5F). It is clearly seen that, for wt and the mutants A170G, AC170CA, the telomeres remain short and stable and that, for the mutants A170C and C178A, the telomeres became extended and heterogeneous. These results confirmed the importance of the reverse transcription of 
the nontelomeric A170 nucleotide for telomerase action and telomere biogenesis in $H$. polymorpha in vivo.

\section{DISCUSSION}

\section{Analysis of the HpTER structure}

Previously, the telomerase reverse transcriptase from $H$. polymorpha was successfully expressed and purified (Smekalova et al. 2012). In this study telomerase RNA from H. polymorpha was identified; a secondary structure model, incorporating a number of conserved features, was derived (Fig. 2). A $3^{\prime}$ RACE analysis allowed us to isolate different forms of HpTER (Supplemental Fig. S4). Most likely, long polyadenylated forms (between 792 and 824) represent primary transcripts. HpTER transcript polyadenylation is in agreement with the fact that the telomerase RNA moiety usually contains a portion of polyadenylated forms (Chapon et al. 1997). Short forms (680-689) were not polyadenylated and may result from HpTER processing.

Similar to the TLC1 RNA, the HpTER secondary structure model contains three helical arms (Fig. 2). A putative pseudoknot (Fig. 2), containing a triple helical element essential for telomerase RNA functioning (Theimer and Feigon 2006), covers nucleotides 368-457 and includes the nucleotides 396-399 (5'-AUGA-3') of the CS3 hairpin conserved in all studied telomerase RNAs in fungi (Gunisova et al. 2009; Qi et al. 2013).

An important feature of $S$. cerevisiae TER is the Est1 binding hairpin located between the pseudoknot and the template region (Seto et al. 2002). In the HpTER secondary structure model, a putative Est1 hairpin is formed by nucleotides 252332. Analysis of this element revealed the consensus sequences corresponding to the CS2 (5'-GAAUG-3') and CS2a (5'CUUCA-A-GG-3') elements of TERs from Candida species (Fig. 2; Gunisova et al. 2009). A putative three-way junction element (TWJ) is formed by nucleotides 526-576. This putative structure contains the P6.1-like element of vertebrate TRs that is highly conserved between all the species (Brown et al. 2007; Qi et al. 2013) and found to be essential for telomerase activity in fungi (Qi et al. 2013). The L2 linker (single adenosine) and the first Watson-Crick AU pair in S3 hairpin are conserved in telomerase RNA of vertebrate and budding yeast, and they are present in the HpTER secondary structure model. In the case of HpTER, the putative linker L3 is made of nucleotides ${ }^{568}$ GUCGA ${ }^{572}$ (Fig. 2), whereas it consists of 2 nt $\left(5^{\prime}-\mathrm{GU}-3^{\prime}\right)$ in most yeast and $4 \mathrm{nt}\left(5^{\prime}\right.$-GUCA-3') in vertebrates (Gunisova et al. 2009).

It has been shown that the first step of splicing is essential for telomerase RNA biogenesis in fission yeast S. pombe (Box et al. 2008a). Splicing sites were detected in silico for telomerase RNA from Candida species, yet biochemically the significance of that splicing was not shown (Gunisova et al. 2009). The HPTER gene contains sequences that match the $5^{\prime}$ splice site $\left({ }^{690} \mathrm{GUGAGU}{ }^{695}\right)$ and the splicing branch point $\left({ }^{720}\right.$ UACUAAC $\left.^{726}\right)$ (Fig. 2, Supplemental Fig. S2); mutations in the putative $5^{\prime}$ splice site and branch point were significant for RNA maturation (Supplemental Fig. S6). RNA 3' RACE analysis (Supplemental Fig. S2) also confirmed the predictions. One of the short abundant forms (689 nt) corresponded to the expected maturation product of the first splicing cleavage reaction. In Hansenula, the $3^{\prime}$ splice site consists of only 3 nt, which makes identification difficult (Blandin et al. 2000). Among the RACE clones, we were able to detect a full splicing product with an excised intron that allowed us to propose the position of the $3^{\prime}$-splice site $\left({ }^{738} \mathrm{CAU}^{740}\right)$. These data suggest that the mechanism of HpTER processing includes participation of the spliceosomal machinery in the same way that it takes place for $S$. pombe telomerase RNA (Kannan et al. 2013).

The Ku70/Ku80 binding hairpin, found in other yeast (Stellwagen et al. 2003), is absent in the predicted model. This is an important, yet genetically not essential, element that mediates the interaction between telomerase and telomeres in yeast during cell cycle. Its absence in $H$. polymorpha species agrees with the previous suggestion that the element is not evolutionary preserved even in yeast telomerase RNAs (Egan and Collins 2012).

A conserved element in TER sequence in many yeast species is the Sm binding site at its $3^{\prime}$ end (Dandjinou et al. 2004). Yeast consensus for Sm site is " $\mathrm{AU}_{(5-6)} \mathrm{GPu}$ " (Jones and Guthrie 1990). The HPTER gene lacks this exact pattern, although it contains several potential sequences that could provide putative Sm site: ${ }^{683}{ }^{A U U U C C U G}{ }^{690}$ and ${ }^{675} \mathrm{AUCCUG}^{680}$. Interestingly, no canonical Sm site could be detected in case of $N$. crassa telomerase as well (Qi et al. 2013).

The putative template boundary element was identified in the HpTER secondary structure model (Fig. 2) and the necessity for cell viability of its secondary structure was confirmed by mutagenesis (Supplemental Fig. S5).

We showed that $H$. polymorpha telomerase reverse transcribes only 9-nt region (178-170) of the template (Fig. 4A, B). The adjacent segment of $9 \mathrm{nt}$, from 187 to 179 , can potentially serve as a "primer-alignment" region. These elements are located in the single-stranded region adjacent to the putative TBE in the RNA secondary structure model (Fig. 2).

\section{Incorporation of nontelomeric dT to the very end of telomere mediates telomere length control system}

Hansenula polymorpha telomerase adds a nontelomeric nucleotide during telomere synthesis in vitro and in vivo (Fig. 4). Not all telomerases reproduce an exact telomerase RNA template sequence, and this results in telomere heterogeneity as detected in protozoa, some yeast species, slime molds, and plants (McCormick-Graham et al. 1997; Wellinger and Sen 1997; Förstemann and Lingner 2001). The divergence in telomeric repeats is most strikingly observed in $S$. pombe and $S$. cerevisiae. The causes for this degeneracy include multiple primer alignment registers in the RNA template, abortive 
reverse transcription, the slippage of the substrate on the RNA template, and the low fidelity of the enzyme (Förstemann and Lingner 2001; Leonardi et al. 2008). Such heterogeneity can be also observed in internal parts of Hansenula polymorpha telomeres as revealed by the analysis of reads from $H$. polymorpha whole genome shotgun sequences. However, the incorporation of a nontelomeric nucleotide at the very end of telomeres by $H$. polymorpha telomerase both in vitro and in vivo (Fig. 4) is not due to mechanisms mentioned above but to the reverse transcription of A170 present in the telomerase template.

There are a number of examples when telomerase reverse transcribes beyond the template, but all these events are associated with mutations in telomerase components. Indeed, disrupting interactions in the TBE in different TERs can lead to transcription of the sequence following the template, rearrangement of the telomerase RNA structure, and a change in the processivity of telomerase (Seto et al. 2003; Box et al. 2008b; Booy et al. 2012). TERT is known to contribute to stabilization of the template boundary element through direct interactions in different species including $S$. cerevisiae, T. thermophila (Miller et al. 2000; Lai et al. 2002; Seto et al. 2003). Mutations in the C-terminal domain of hTERT were shown to mediate template definition; partial deletions of the hTERT C terminus resulted in reverse transcription proceeding beyond the template (Moriarty et al. 2005). However, the results obtained so far for wild-type telomerases have not provided evidence for reverse transcription of a nontelomeric sequence in vitro or in vivo. The nontelomeric $\mathrm{dT}$ could be incorporated during each elongation step and should then be removed for further productive telomere elongation as the inability of telomerase to elongate the nontelomeric $5^{\prime}$ (GGGTGGCG) ${ }_{3}$ GGGTGGCGT-3' sequence in vitro of telomeres indicates.

Nuclease activity is known to be associated with human and yeast telomerase (Petrov et al. 1998; Huard and Autexier 2004). This nuclease activity can be responsible for eliminating the nontelomeric nucleotide after every round of telomeric repeat synthesis. Alternatively, an extra nucleotide could be added only at the very end of telomere when telomerase is switched to a nonprocessive mode. It should be mentioned that a similarly important functional activity was previously discovered for Tetrahymena telomerase. In that case, an extra nucleotide can be added, followed by a switch of telomerase to a nonprocessive mode and then removal through its $3^{\prime}-5^{\prime}$ nucleolytic activity (Collins and Greider 1993).

The fact that $90 \%$ of telomere ends contain the nontelomeric $\mathrm{dT}$ nucleotide indicates that this extra nucleotide serves as a marker for the end of a chromosome that has just been subjected to processing by telomerase and may be involved in telomere capping.

We showed that the reverse transcription of A170 resulting in the incorporation of a nontelomeric nucleotide at the very end of telomeres had an impact on telomere length in $H$. poly- morpha yeast (Fig. 5). The strain with the A170C mutation in the telomerase RNA, that yields a product fully complementary to the telomeric sequence, possessed elongated and heterogeneous telomeres compared to the wild-type strain. Notably, the A170G mutation led to the incorporation of another nontelomeric nucleotide. In this mutant, telomeres remained homogeneous with length kept at its initial level. Also, the double mutation AC170CA provided telomeres close to the wild-type strain. These results indicate that telomere elongation in A170C resulted from changes in the DNA sequence produced by telomerase rather than from changes in the enzyme structure. It also implies that the incorporation of a nontelomeric nucleotide at the end of the synthesis round is part of the telomere length control system. Indeed, we were able to impair this system by another mutation (C178A). In this mutant, we introduced the possibility for a newly synthesized telomeric repeat with an extra dT at the very end to become fully complementary to the template region of TER. That immediately resulted in the appearance of highly heterogeneous and extended telomeres (Fig. 5). Taken together, our data allow us to propose that the incorporation of a nontelomeric nucleotide at the telomere end is a part of a system for telomere length maintenance in $H$. polymorpha.

The control of telomere length is complicated and varies with species. It involves cooperation between telomere maintenance, elongation, and shortening (Gilson and Géli 2007). A number of genes are found responsible for the mediation of the telomere length in various organisms. Regulation is usually associated with action of subtelomeric and telomeric protein factors that regulate telomerase activity in vivo (Smogorzevska and de Lange 2004; Schoeftner and Blasco 2009; Nandakumar and Cech 2013). The available data indicate that the binding of protein factors on telomere acts as a mechanical block, limiting accessibility of the substrate to the enzyme. Little is known about the participation of telomerase itself in the telomere length restriction. For S. cerevisiae it has been shown that the finger domain of the telomerase catalytic subunit is involved in negative control of the telomerase, because mutation in this region led to telomere lengthening (Eugster et al. 2006). Here, we provide evidence that the telomerase RNA contributes to the mechanism of telomere length restriction in $H$. polymorpha yeast. Considering the short length of $H$. polymorpha telomeres, it is possible that the organism has evolved in such a way that it developed a peculiar system of telomere length restriction. The possibility also exists that participation of the telomerase core complex in telomere length limitation is a common feature in other species.

\section{MATERIALS AND METHODS}

\section{Obtaining antibodies against HPTERT}

We generated polyclonal antibodies against HpTERT by immunization of the rabbit with the usage of Freund's Complete Adjuvant according to manufacturers' recommendations. Purified HpTERT 
(0.01 mg) (Smekalova et al. 2012) was subjected to 10\% denaturing SDS-PAGE. The band corresponding to the HpTERT protein was sliced out of the gel after electrophoresis, and then the protein was electroeluted to the buffer, containing $20 \mathrm{mM}$ Tris, $200 \mathrm{mM}$ glycine, and $0.1 \%$ SDS. A rabbit was immunized with the resulting sample three times; the first interval between immunizations was $2 \mathrm{wk}$, the second interval was $4 \mathrm{wk}$. The rabbit serum was periodically tested for the ability to bind the protein of interest by Western blot analysis. Escherichia coli extracts expressing recombinant HpTERT were subjected to $10 \%$ SDS-PAGE gel. Proteins were transferred to PVDF membrane (Amersham Hybond P); Western blotting was performed according to the manufacturer's instructions. Series of serum dilutions in PBS-T $(1: 100 ; 1: 500,1: 5000)$ were used as primary antibodies; secondary antibody (peroxidase-conjugated goat anti-rabbit antibody [Boehringer Mannheim]) were used in a dilution of 1:5000. After 3 mo, the derived antiserum was further purified on a membrane carrying HpTERT, as described (Walker 1996).

\section{Telomerase isolation and assay}

Purification of telomerase was performed as described (Cohn and Blackburn 1995). Briefly, cells were harvested in early log phase, disintegrated in liquid nitrogen, and resuspended in TMG50 buffer (10 $\mathrm{mM}$ Tris/ $\mathrm{HCl}[\mathrm{pH}=8], 1.2 \mathrm{mM} \mathrm{MgCl}_{2}, 10 \%$ glycerol, $0.1 \mathrm{mM}$ EDTA, 0.1 mM EGTA, $0.1 \mathrm{mM}$ DTT, $50 \mathrm{mM}$ NaOAc, RNasin [10 units $/ \mathrm{mL}]$, supplied with the protease inhibitor cocktail complete mini [Roche Applied Science]). Derived S100 supernatant was subjected to ion exchange chromatography on DEAE sepharose (Biogel; Bio-Rad). We applied $30 \mathrm{mg}$ total protein with concentration 0.25 $\mathrm{mg} / \mathrm{mL}$ per $2 \mathrm{~mL}$ DEAE column equilibrated with TMG50 buffer, the gel was washed with $45 \mathrm{~mL}$ TMG50, and then NaOAc salt gradient $(0.05-1 \mathrm{M} 30 \mathrm{~mL})$ was performed. In vitro telomerase assay was held under the following conditions: 50\% DEAE fraction, 50 $\mathrm{mM}$ Tris/ $\mathrm{HCl}(\mathrm{pH}=8), 1 \mathrm{mM}$ spermidine, $1 \mathrm{mM}$ DTT, $50 \mu \mathrm{M}$ dNTP, $1 \mu \mathrm{M}$ oligonucleotide, and $3.75 \mu \mathrm{M} \alpha-{ }^{32} \operatorname{PdGTP}(800 \mathrm{Ci} /$ $\mathrm{mmol}$ ). The reaction products were analyzed on $10 \%$ denaturing PAGE. The markers were generated by radioactive labeling of the corresponding oligonucleotides using T4 PNK (Fermentas).

\section{Identification of the telomerase RNA $5^{\prime}$ end}

Total RNA was isolated as described in Hanna and Xiao (2006b). cDNA synthesis and PCR were performed using $5^{\prime}$ RACE System for Rapid Amplification of cDNA Ends (Invitrogen) according to manufacturer's instructions. The deoxyribonucleotide qR0r (5'TGGACGTCTCCATTTGTTGAC-3') primed cDNA synthesis and was used as a forward primer in the PCR. The PCR products were cloned and sequenced.

\section{Identification of the telomerase RNA $3^{\prime}$ end}

Total RNA was isolated as described in Hanna and Xiao (2006b). A portion of RNA was polyadenylated using Poly(A) Tailing Kit (Ambion) according to manufacturer's instructions. cDNA synthesis and PCR was performed using 3' RACE System for Rapid Amplification of cDNA Ends (Invitrogen) according to manufacturer's instructions. The qRf primer (5'-ATGCTGTCGGTCCCACT
AAC- $3^{\prime}$ ) was used as a forward primer in the PCR. The PCR products were cloned and sequenced.

Five hundred microliters of the DEAE fraction, containing telomerase isolated as described in the previous section, was precipitated and treated with 100 units of amplification grade DNAse1 (Invitrogen). The RNA was precipitated again and treated with solution, containing 10 units T4 RNA ligase (Fermentas), $40 \mu \mathrm{M}$ RNA oligonucleotide $3^{\prime} \mathrm{RNA}$-adaptor 5'-(PO4)UCGUAUGCCGUCUU CUGCUUG(ddC)- $3^{\prime}, 10$ units of RNasine (Fermentas) in $1 \times$ buffer for T4 RNA ligation (Fermentas); reaction was performed in $10 \mu \mathrm{L}$ overnight under room temperature. Another precipitation was held, followed by RT-PCR with primers for Adaptor 5'-CAAGCAGAAG ACGGCATACGA-3' , and 3'RNAsearch 5'-CAGACCATCGCACCA TATCGC-3' (OneStep RT-PCR KIT, QIAGEN). The products were cloned and sequenced.

\section{Yeast strains and media}

The taxonomy of $H$. polymorpha is still under discussion (Suh and Zhou 2010). In this work, we used two different strains of the H. polymorpha species. The HpTERT gene was cloned from ATCC 34438 (CBS4732) type strain of P. angusta (a.k.a. Ogataea polymorpha). Telomerase isolation and the telomerase RNA gene were derived from DL-1 (ATCC 26012) strain of H. polymorpha. Strains were kindly provided by M.O. Agaphonov (A.N. Bach Institute of Biochemistry RAS). Cells were grown on standard YPD media ( $1 \%$ yeast extract, $2 \%$ peptone, $2 \%$ glucose) under $37^{\circ} \mathrm{C}$. To make knockouts of HPTERT and HPTER, the LEU2 gene of H. polymorpha was used (Agaphonov et al. 1994), derived from pCHLX plasmid, kindly provided by M.O. Agaphonov. The HPTERT gene was interrupted by the site Stu1 at the 1426-nt position, and the LEU2 gene was introduced inside the HPTERT gene, whereas for HPTER knockout, nucleotides from 55 to 563 were replaced with the $L E U$ gene. Transformation of yeast with PCR product was performed with a standard protocol, modified as described (Bogdanova et al. 1995). Transformants, obtained with constructs containing LEU2, were selected on complete minimal medium without leucine (Hanna and Xiao 2006a); the integration was confirmed by PCR from genomic DNA (Supplemental Fig. S2).

\section{$\Delta$ HpTER knockout strain phenotype assay and transformation}

$\triangle$ HpTERT cells and $\triangle$ HpTER\#1 and $\# 2$ transformants (Fig. $1 \mathrm{~A}$ ) were grown overnight (first streak), diluted to equal density $\left(\mathrm{OD}_{600}=\right.$ 0.02 ), and grown overnight again. Every day 4, serial fivefold dilutions of diluted cells (with $\mathrm{OD}_{600}=0.02$ ) were spotted on the YPD plate. This experiment was continued for $7 \mathrm{~d}$ ( 7 streaks).

To compensate HPTER knockout or to introduce mutated telomerase RNA into the $\triangle$ HpTER knockout strain, we used shuttle vector pKAM556 with a modified Tn903 kanamycin resistance gene (Agaphonov et al. 2010). The HPTER gene was inserted into the pKAM556 by Sma1 site resulting in pKAM556_HpTER vector. For selection of G418-resistant transformants, $0.7 \times$ YPD supplemented with $120 \mathrm{mg} / \mathrm{L} \mathrm{G} 418$ was used.

Cells from the stock made from a portion of $\triangle \mathrm{HpTER}$ cells $(\triangle \mathrm{HpTER} \# 2$ transformant in Fig. $1 \mathrm{~A})$ after first streak were grown overnight and used for transformation performed with a standard protocol, modified as described (Bogdanova et al. 1995). Thus, on 
a day of transformation, cells were after the second streak and could no longer yield any colonies on a plate (Fig. 1A), unless transformed with a plasmid with a functional telomerase RNA gene. Transformation with an empty vector without $H P T E R$ gene or a vector with nonfunctional mutant $H p T E R$ gene could not support formation of yeast colonies on the plate either (Supplemental Fig. S6A). Mutations were introduced in pKAM556_HpTER by QuikChange II XL Site-Directed Mutagenesis Kit (Stratagene), and these products were sequenced to confirm mutations of interest and also the absence of secondary mutations in the HPTER gene.

\section{qRT-PCR}

HpU1 snRNA served as an internal control. cDNA was synthesized with HpTER-specific primer (qRr 5'-CCACCACAGCCGTACTTC TC- $3^{\prime}$ ) or with HpU1-specific primer (qHU1r 5'-ACTCCTCC GAAGGGAAGAG-3') using RevertAid Reverse Transcriptase (Thermo Scientific) according to manufacturer's protocol. Real-time PCR reactions were performed in a $25-\mu \mathrm{L}$ mixture containing cDNA preparation, $1 \times$ Taq $\mathrm{KCl}$ buffer, $2.5 \mathrm{mM} \mathrm{MgCl}_{2}, 0.6 \mu \mathrm{M}$ primers, $0.2 \mathrm{mM}$ dNTPs mix, $0.4 \times$ SYBR Green, and 1.5 units of Taq polymerase (Thermo Scientific). Primers for HpTER were qRf 5'-ATGCTGTCGGTCCCACTAAC-3' and $\mathrm{qRr}$ 5'-CCACCACAG CCGTACTTCTC-3'. Primers for HpU1 were qHU1f $5^{\prime}$-GGAGA TCACAGGAGATCATG-3' and qHU1r 5'-ACTCCTCCGAAGGG AAGAG-3'.

\section{Southern hybridization}

For Southern blot (Fig. 1B) $\triangle$ HpTER\#1 transformant was used. Telomere length was analyzed by the standard Southern hybridization technique (Maniatis et al. 1982). Total chromosomal DNA was isolated and digested with EcoR1 restriction endonuclease (Fermentas). After electrophoresis, the DNA was transferred onto a Hybond $\mathrm{N}+$ (Amersham), nylon membrane. Hybridization was performed with the telomeric oligonucleotide G4 5'-(GGGTGG CG) $)_{4}-3^{\prime}$ radiolabeled with $\alpha^{32}$ PdGTP by Terminal Deoxynucleotidyl Transferase (Fermentas).

\section{Telomere PCR and sequencing}

Genomic DNA was isolated as described in (Hanna and Xiao 2006b). DNA oligonucleotides PBoli733 [5'-GCGTACGACTCA CTGTAGATNNNNN-3'-O(CH2)2CH2OH] and PBoli749 (p5'-A TCTACAGTGAGTCGTACGCAA-3' -biotin) were annealed at 100

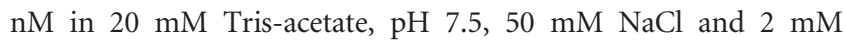
$\mathrm{MgCl}_{2}$ by heating to $95^{\circ} \mathrm{C}$ and slow cooling to room temperature (Leonardi et al. 2008). The partial duplex (0.5 pmol) was then ligated to genomic DNA $(1 \mu \mathrm{g})$ with T4 DNA ligase (Rapid DNA ligation kit, Thermo Scientific). PCR amplification of telomeres was performed with forward primer S12 (5'-AAGCGGCAGAGTTGG TTTCAGGATGC-3') and reverse primer PBoli745 (5'-GCGTA CGACTCACTGTAGAT-3') using GC-RICH PCR System (Roche). Cycling conditions were $3 \mathrm{~min}$ at $95^{\circ} \mathrm{C} ; 0.5 \mathrm{~min}$ at $95^{\circ} \mathrm{C}$, $0.5 \mathrm{~min}$ at $55^{\circ} \mathrm{C}, 0.5 \mathrm{~min}$ at $72^{\circ} \mathrm{C}(30$ cycles $) ; 10 \mathrm{~min}$ at $72^{\circ} \mathrm{C}$. For telomere length, measurement by PCR PfuTurbo DNA polymerase (Stratagene) was used instead of DNA polymerase from the GCRICH PCR System and 35 (instead of 30) cycles of PCR amplification.
The PCR fragments of telomeres from strain DL-1 of H. polymorpha were sequenced on a Roche GS FLX genome sequencer using the Titanium protocol. Sequencing reads that passed the quality filters, containing specific primer sequences, were extracted for further analysis.

\section{DATA DEPOSITION}

The DNA sequences of HPTERT and HPTER genes were submitted to GenBank under the following accession numbers: HPTERT JQ957926 and HpTER JQ957927.

\section{SUPPLEMENTAL MATERIAL}

Supplemental material is available for this article.

\section{ACKNOWLEDGMENTS}

We thank M. Agaphonov (Institute of Experimental Cardiology, Cardiology Research Centre, Moscow, Russia) who kindly provided strains, plasmids, and protocols for $H$. polymorpha genetics. We thank anonymous reviewers for the huge effort contributed to improving this publication. The study was supported by The Ministry of Education and Science of the Russian Federation, project No. 8297; Russian Foundation for Basic Research (Grants 11-04-01310a; 12-04-92429-EMBL_a; 13-00-40197-K); Program Molecular and Cellular Biology of the Russian Academy of Sciences (A.V.M. and N.V.R.); PNR 5.13; and the International Associated Laboratory LIA-NUCPROT (CNRS-Russia).

Received January 31, 2013; accepted July 16, 2013.

\section{REFERENCES}

Agaphonov MO, Poznyakovski AI, Bogdanova AI, Ter-Avanesyan MD. 1994. Isolation and characterization of the LEU2 gene of Hansenula polymorpha. Yeast 10: 509-513.

Agaphonov M, Romanova N, Choi ES, Ter-Avanesyan M. 2010. A novel kanamycin/G418 resistance marker for direct selection of transformants in Escherichia coli and different yeast species. Yeast 27: 189-195.

Blackburn EH. 2000. The end of the (DNA) line. Nat Struct Biol 7: 847-850.

Blandin G, Llorente B, Malpertuy A, Wincker P, Artiguenave F, Dujon B. 2000. Genomic exploration of the hemiascomycetous yeasts: 13 . Pichia angusta. FEBS Lett 487: 76-81.

Bogdanova AI, Agaphonov MO, Ter-Avanesyan MD. 1995. Plasmid reorganization during integrative transformation in Hansenula polymorpha. Yeast 11: 343-353.

Booy EP, Meier M, Okun N, Novakowski SK, Xiong S, Stetefeld J, McKenna SA. 2012. The RNA helicase RHAU (DHX36) unwinds a G4-quadruplex in human telomerase RNA and promotes the formation of the P1 helix template boundary. Nucleic Acids Res 40: 4110-4124.

Box JA, Bunch JT, Tang W, Baumann P. 2008a. Spliceosomal cleavage generates the 3' end of telomerase RNA. Nature 456: 910-914.

Box JA, Bunch JT, Zappulla DC, Glynn EF, Baumann P. 2008b. A flexible template boundary element in the RNA subunit of fission yeast telomerase. JBC 283: 24224-24233.

Brown Y, Abraham M, Pearl S, Kabaha MM, Elboher E, Tzfati Y. 2007. A critical three-way junction is conserved in budding yeast and vertebrate telomerase RNAs. Nucleic Acids Res 35: 6280-6289. 
Chapon C, Cech TR, Zaug AJ. 1997. Polyadenylation of telomerase RNA in budding yeast. RNA 3: 1337-1351.

Cohn M, Blackburn EH. 1995. Telomerase in yeast. Science 269: 396400.

Collins K. 2006. The biogenesis and regulation of telomerase holoenzymes. Nat Rev Mol Cell Biol 7: 484-494.

Collins K, Greider CW. 1993. Tetrahymena telomerase catalyzes nucleolytic cleavage and nonprocessive elongation. Genes Dev 7: $1364-1376$.

Dandjinou AT, Lévesque N, Larose S, Lucier JF, Abou Elela S, Wellinger RJ. 2004. A phylogenetically based secondary structure for the yeast telomerase RNA. Curr Biol 14: 1148-1158.

Darty K, Denise A, Ponty Y. 2009. VARNA: Interactive drawing and editing of the RNA secondary structure. Bioinformatics 25: 1974-1975.

Egan ED, Collins K. 2012. Biogenesis of telomerase ribonucleoproteins. RNA 18: 1747-1759.

Eldarov MA, Mardanov AV, Beletsky AV, Ravin NV, Skryabin KG. 2011. Complete sequence and analysis of the mitochondrial genome of the methylotrophic yeast Hansenula polymorpha DL-1. FEMS Yeast Res 11: 464-472.

Eugster A, Lanzuolo C, Bonneton M, Luciano P, Pollice A, Pulitzer JF, Stegberg E, Berthiau AS, Förstemann K, Corda Y, et al. 2006. The finger subdomain of yeast telomerase cooperates with Pif1p to limit telomere elongation. Nat Struct Mol Biol 13: 734-739.

Förstemann K, Lingner J. 2001. Molecular basis for telomere repeat divergence in budding yeast. Mol Cell Biol 21: 7277-7286.

Gilson E, Géli V. 2007. How telomeres are replicated. Nat Rev Mol Cell Biol 8: 825-838.

Greider CW. 1991. Telomerase is processive. Mol Cell Biol 11: 45724580.

Gunisova S, Elboher E, Nosek J, Gorkovoy V, Brown Y, Lucier J-F, Laterreur N, Wellinger RJ, Tzfati Y, Tomaska L. 2009. Identification and comparative analysis of telomerase RNAs from Candida species reveal conservation of functional elements. RNA 15: 546-559.

Hanna M, Xiao W. 2006a. Yeast protocols. Methods Mol Biol 313: 4-6.

Hanna M, Xiao W. 2006b. Yeast protocols. Methods Mol Biol 313: $15-20$.

Huard S, Autexier C. 2004. Human telomerase catalizes nucleolytic primer cleavage. Nucleic Acids Res 32: 4059-4070.

IJpma AS, Greider CW. 2003. Short telomeres induce a DNA damage response in Saccharomyces cerevisiae. Mol Biol Cell 14: 987-1001.

Jones MH, Guthrie C. 1990. Unexpected flexibility in an evolutionarily conserved protein-RNA interaction: Genetic analysis of the Sm binding site. EMBO J 9: 2555-2561.

Jossinet F, Westhof E. 2005. Sequence to Structure (S2S): Display, manipulate and interconnect RNA data from sequence to structure. Bioinformatics 21: 3320-3321.

Kachouri-Lafond R, Dujon B, Gilson E, Westhof E, Fairhead C, Teixeira MT. 2009. Large telomerase RNA, telomere length heterogeneity and escape from senescence in Candida glabrata. FEBS Lett 583: 3605-3610.

Kannan R, Hartnett S, Voelker RB, Berglund JA, Staley JP, Baumann P. 2013. Intronic sequence elements impede exon ligation and trigger a discard pathway that yields functional telomerase RNA in fission yeast. Genes Dev 27: 627-638.

Lai CK, Miller MC, Collins K. 2002. Template boundary definition in Tetrahymena telomerase. Genes Dev 16: 415-420.

Leonardi J, Box JA, Bunch JT, Baumann P. 2008. TER1, the RNA subunit of fission yeast telomerase. Nat Struct Mol Biol 15: 26-33.

Levine DW, Cooney CL. 1973. Isolation and characterization of a thermotolerant methanol-utilizing yeast. Appl Microbiol 26: 982-990.

Lingner J, Hughes TR, Shevchenko A, Mann M, Lundblad V, Cech TR 1997. Reverse transcriptase motifs in the catalytic subunit of telomerase. Science 276: 561-567.
Lue NF. 2004. Adding to the ends: What makes telomerase processive and how important is it? Bioassays 26: 955-962.

Maniatis T, Fritsch EF, Sambrook J. 1982. Molecular cloning: A laboratory manual. Cold Spring Harbor Laboratory, Cold Spring Harbor, NY.

McCormick-Graham M, Haynes WJ, Romero DP. 1997. Variable telomeric repeat synthesis in Paramecium tetraurelia is consistent with misincorporation by telomerase. EMBO J 16: 3233-3242.

Miller M, Liu J, Collins K. 2000. Template definition by Tetrahymena telomerase reverse transcriptase. EMBO J 19: 4412-4422.

Moriarty TJ, Marie-Egyptienne DT, Autexier C. 2005. Regulation of the $5^{\prime}$ template usage and incorporation of noncognate nucleotides by human telomerase. RNA 11: 1448-1460.

Nandakumar J, Cech TR. 2013. Finding the end: Recruitment of telomerase to telomeres. Nat Rev Mol Cell Biol 14: 69-82.

Petrov AV, Dokudovskaya SS, Sokolov KA, Lavrik OI, Favre A, Dontsova OA, Bogdanov AA. 1998. Telomerase from Saccharomyces cerevisiae contains several protein subunits and may have different activities depending on the protein content. FEBS Lett 436: $35-40$

Qi X, Li Y, Honda S, Hoffmann S, Marz M, Mosig A, Podlevsky JD, Stadler PF, Selker EU, Chen JJ. 2013. The common ancestral core of vertebrate and fungal telomerase RNAs. Nucleic Acids Res 41: $450-462$.

Schoeftner S, Blasco MA. 2009. A 'higher order' of telomere regulation: Telomere heterochromatin and telomeric RNAs. EMBO J 28: 23232336.

Seto AG, Livengood AJ, Tzfati Y, Blackburn EH, Cech TR. 2002. A bulged stem tethers Estlp to telomerase RNA in budding yeast. Genes Dev 16: 2800-2812.

Seto AG, Umansky K, Tzfati Y, Zaug AJ, Blackburn EH, Cech TR. 2003. A template-proximal RNA paired element contributes to Saccharomyces cerevisiae telomerase activity. RNA 9: 1323-1332.

Sfeir AJ, Chai W, Shay JW, Wright WE. 2005. Telomere-end processing the terminal nucleotides of human chromosomes. Mol Cell 18: 131-138.

Smekalova EM, Petrova OA, Zvereva MI, Dontsova OA. 2012. Hansenula polymorpha TERT: A telomerase catalytic subunit isolated in recombinant form with limited reverse transcriptase activity. Acta Naturae 4: 70-73.

Smogorzevska A, de Lange T. 2004. Regulation of telomerase by telomeric proteins. Annu Rev Biochem 73: 177-208.

Sohn JH, Choi E-S, Kang HA, Rhee J-S, Rhee S-K. 1999. A family of telomere-associated autonomously replicating sequences and their functions in targeted recombination in Hansenula polymorpha DL-1.J Bacteriol 181: 1005-1013.

Stellwagen AE, Haimberger ZW, Veatch JR, Gottschling DE. 2003. $\mathrm{Ku}$ interacts with telomerase RNA to promote telomere addition at native and broken chromosome ends. Genes Dev 17: 23842395

Suh SO, Zhou JJ. 2010. Methylotrophic yeasts near Ogataea (Hansenula) polymorpha: A proposal of Ogataea angusta comb. nov. Candida parapolymorpha sp. nov. FEMS Yeast Res 10: 631-638.

Theimer CA, Feigon J. 2006. Structure and function of telomerase RNA. Curr Opin Struct Biol 16: 307-318.

Walker JM. 1996. The protein Protocols Handbook: A laboratory manual. Humana Press, Totowa, NJ.

Webb CJ, Zakian VA. 2008. Identification and characterization of the Schizosaccharomyces pombe TER1 telomerase RNA. Nat Struct Mol Biol 15: 34-42.

Wellinger RJ, Sen D. 1997. The DNA structures at the ends of eukaryotic chromosomes. Eur J Cancer 33: 735-749.

Zuker M. 2003. Mfold web server for nucleic acids and hybridization prediction. Nucleic Acids Res 31: 3406-3415. 

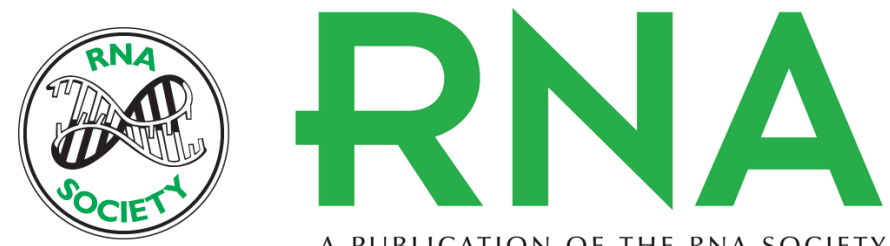

A PUBLICATION OF THE RNA SOCIETY

\section{Specific features of telomerase RNA from Hansenula polymorpha}

Elena M. Smekalova, Alexander N. Malyavko, Maria I. Zvereva, et al.

RNA 2013 19: 1563-1574 originally published online September 17, 2013

Access the most recent version at doi:10.1261/rna.038612.113

Supplemental Material

References

Creative Commons License

Email Alerting Service
http://rnajournal.cshlp.org/content/suppl/2013/08/08/rna.038612.113.DC1

This article cites 54 articles, 20 of which can be accessed free at: http://rnajournal.cshlp.org/content/19/11/1563.full.html\#ref-list-1

This article is distributed exclusively by the RNA Society for the first 12 months after the full-issue publication date (see http://rnajournal.cshlp.org/site/misc/terms.xhtml). After 12 months, it is available under a Creative Commons License (Attribution-NonCommercial 3.0 Unported), as described at http://creativecommons.org/licenses/by-nc/3.0/.

Receive free email alerts when new articles cite this article - sign up in the box at the top right corner of the article or click here.

To subscribe to $R N A$ go to:

http://rnajournal.cshlp.org/subscriptions 